\title{
REVIEW
}

\section{Andrology in China: current status and 10 years' progress}

\author{
Kai Hong ${ }^{1}$, Qing-Quan $\mathrm{Xu}^{2}$, Yong-Ping Zhao ${ }^{2}$, Yi-Qun Gu${ }^{3}$, Hui Jiang ${ }^{1}$, Xiao-Feng Wang ${ }^{2}$ and Ji-Chuan Zhu ${ }^{2}$ \\ Andrology has a long history in traditional Chinese medicine. There are records of male sexual health, male sexual dysfunction and male \\ infertility from over thousands of years ago. Modern andrology in China had a late start, with the Chinese Andrology Association founded \\ in 1995. Within last decade, andrology in China has grown rapidly. In this review article, we summarized the progress of andrology in \\ last 10 years and outlined the current status of Chinese andrology with a special focus on progress in male erectile dysfunction, prostate \\ diseases, male infertility and male hormonal contraception.
}

Asian Journal of Andrology (2011) 13, 512-518; doi:10.1038/aja.2010.123; published online 6 June 2011

Keywords: andrology; benign prostatic hyperplasia; Chinese; contraception; erectile dysfunction; male infertility; prostate cancer; prostatitis

\section{INTRODUCTION}

Andrology has a long history in traditional Chinese medicine. There are records of male sexual health, male sexual dysfunction and male infertility from thousands of years ago. Modern andrology in China had a late start, with the Chinese Andrology Association founded in 1995. There are branches of the andrology association in 23 provinces. Andrology is also covered by the Chinese Urology Association, the Chinese Sexual Medicine Association and the Chinese Traditional Medicine Association. There are three core journals, National Journal of Andrology, Asian Journal of Andrology and Chinese Journal of Andrology.

In 2007, the Chinese Andrology Association issued its first edition guidelines on erectile dysfunction (ED), male infertility and late-onset hypogonadism. Guidelines on benign prostatic hyperplasia, prostate cancer $(\mathrm{PCa})$ and prostatitis were issued by the Chinese Urology Association. There are three andrology conferences each year: the annual meeting of the Chinese Andrology Association, the Chinese Andrology Forum and the Asia-Pacific Forum on Andrology. These conferences afford andrologists and urologists the opportunity to communicate.

In this paper, we summarized the current state of Chinese Andrology with a special focus on the progress that has been made in male $\mathrm{ED}$, prostatic diseases, male infertility and male hormonal contraception.

\section{ERECTILE DYSFUNCTION}

With the development of oral phosphodiesterase type 5 inhibitors (PDE5is), therapy for ED has been brought into a new era, and a growing number of clinical and basic science research papers have been published in the last decade. At the same time, Chinese Andrology has progressed rapidly. This review focuses on the progress of the last ten years with regard to ED studies in China.

\section{Epidemiology of ED in China}

With the publication of the Massachusetts Male Aging Study in the 1980s, physicians began to realize that ED is more prevalent than previously expected. In China, we have observed that the prevalence of ED (Table 1$)^{1-8}$ is as high as that in Western countries. Age is the highest risk factor, but other risk factors include diabetes, cardiac disease and smoking. The data suggest that patients and physicians must be aware of the important association between ED and cardiac diseases. As urologists and andrologists in China, we should bear in mind that ED may be a predictor for cardiac diseases.

International Index of Erectile Function (IIEF) questionnaire is used in the majority of published studies to diagnose the erectile potency and is accepted by most urologists worldwide. We, however, believe that a modified IIEF, an EF survey with the Chinese Index of Erectile Function (CIEF), is more suitable for Chinese ED patients. For example, Zhang et al. ${ }^{7}$ studied the prevalence of ED in three Chinese cities using CIEF that was administered by trained interviewers.

\section{Diagnosis of ED in China}

Over time, approaches to the diagnosis of $\mathrm{ED}$ are variously developed. Currently, the most useful tool for evaluation is the IIEF questionnaire. Wan et al. ${ }^{9}$ used the NEVA to estimate the severity of ED in patients. However, because most patients found NEVA uncomfortable when sleeping, it is not favoured by patients or physicians. However, colour Doppler is well accepted by urologists for examining blood flow in the penile corpus cavernosum. Li et al. ${ }^{10}$ found that the helicine arteries of the penis play an important role in the process of penile erection and that morphology and haemodynamics can be used for the assessment of ED. Furthermore, the vascular indication of sexual excitation response by intracavernous injection of PGE1 is an effective diagnostic tool for ED. It might be of value in differential diagnoses between arterial and venous ED. ${ }^{11}$ Bai et al. ${ }^{12}$ reviewed 183 cases of ED

\footnotetext{
${ }^{1}$ Urology Department, Peking University 3rd Hospital, Beijing 100191, China; ${ }^{2}$ Department of Urology, Peking University People's Hospital, Beijing 100044, China and ${ }^{3}$ Department of Male Clinic Research, National Research Institute for Family Planning, Beijing 100081, China Correspondence: Dr JC Zhu (zhujc1939@sina.com)
}

Received: 6 December 2010; Revised: 24 January 2011; Accepted: 1 March 2011; Published online: 6 June 2011 
Table 1 Prevalence of ED in China ${ }^{1-8}$

\begin{tabular}{|c|c|c|c|c|}
\hline Study & Study design & Diagnose tool & Patients & Prevalence \\
\hline $\begin{array}{l}\text { Zhang et al. } \\
\qquad(2003)^{1}\end{array}$ & $\begin{array}{l}\text { Data including basic demology information, } \\
\text { history of ED, medication etc. were } \\
\text { collected by trained interviewers. }\end{array}$ & IIEF-5 & $\begin{array}{l}1247 \text { married men in the Beijing } \\
\text { urban area }\end{array}$ & $\begin{array}{l}\text { 1. Mean prevalence: } 39.1 \% \text {; } \\
\text { 2. } 54.5 \% \text { (over } 40 \text { years old); } \\
\text { 3. Complete ED in the } 60 \text { - to } 69 \text {-year-old group is } \\
\text { nearly five times as high as in the } 50 \text { - to } 59 \text {-year- } \\
\text { old group. }\end{array}$ \\
\hline Hu et al. $(2003)^{2}$ & $\begin{array}{l}\text { Investigating the prevalence of ED in cardiac } \\
\text { outpatients older than } 35 \text { years in Beijing, } \\
\text { China }\end{array}$ & IIEF-5 & 6848 patients over 35 years old & $\begin{array}{l}\text { 1. } 84.5 \% \text { (elevated compared with people without } \\
\text { cardiac diseases);. } \\
\text { 2. Of these patients, only } 24.1 \% \text { were aware of an } \\
\text { ED problem, and } 3.2 \% \text { visited a clinic. }\end{array}$ \\
\hline Fu et al. $(2001)^{3}$ & $\begin{array}{l}\text { Investigating the incidence of ED in different } \\
\text { ethnic groups in China }\end{array}$ & IIEF-5 & $\begin{array}{l}5504 \text { men in Nanning and Yulin } \\
\text { of Guangxi Province }\end{array}$ & $\begin{array}{l}\text { 1. The incidence of ED among those of the Zhuang } \\
\text { nationality is much higher than among those of } \\
\text { the Han nationality; } \\
\text { 2. There is a distinct difference between men over } \\
40 \text { years old }(24-26 \%) \text { and those under } 40 \text { years } \\
\text { old ( } 15-18 \%)(P<0.01) \text {; } \\
\text { 3. In populations over } 60 \text { years old, the incidence } \\
\text { of ED increases dramatically from } 24 \% \text { to } 87 \% \text {. }\end{array}$ \\
\hline Wang et al. $(2004)^{4}$ & $\begin{array}{l}\text { Investigating the prevalence of ED in elderly } \\
\text { men }\end{array}$ & IIEF-5 & 272 elderly males & $\begin{array}{l}\text { 1. Total prevalence of } \mathrm{ED} \text { is } 89.7 \% \text {; } \\
\text { 2. Prevalences were } 75.9 \%, 78.6 \% \text { and } 100 \% \text { for } \\
60-, 70-\text {, and } 80 \text {-year-olds, respectively; } \\
\text { 3. Among ED patients, } 95.1 \% \text { were diagnosed with } \\
\text { primary hypertension }(P<0.05) \text {. }\end{array}$ \\
\hline Liu et al. $(2006)^{5}$ & $\begin{array}{l}\text { Studying the risk factors for diabetic erectile } \\
\text { dysfunction (DED) and the prevalence of } \\
\text { DED in males with type } 2 \text { diabetes mellitus } \\
\text { (T2DM) }\end{array}$ & IIEF-5 & 226 T2DM patients & $\begin{array}{l}\text { 1. The prevalence of DED in males with T2DM was } \\
67.7 \% \text {; } \\
\text { 2. Risk factors included DM duration, age, } \\
\text { hypertension, smoking and alcohol consumption. }\end{array}$ \\
\hline Xu et al. $(2000)^{6}$ & $\begin{array}{l}\text { Analyzing the clinical characteristics of } 140 \\
\text { ED cases }\end{array}$ & IIEF & 140 ED cases & $\begin{array}{l}\text { 1. The results indicate that patients over } 50 \text { years } \\
\text { old are at higher risk and tend to have worse ED; } \\
\text { 2. The erectile function (EF) domain is a simple and } \\
\text { practical means to evaluate ED. }\end{array}$ \\
\hline $\begin{array}{l}\text { Zhang et al. } \\
\qquad(2003)^{7}\end{array}$ & $\begin{array}{l}\text { Studying the prevalence of ED in three } \\
\text { Chinese cities in China }\end{array}$ & CIEF & $\begin{array}{l}2226 \text { subjects from Beijing, } \\
\text { Chongqing, and Guangzhou were } \\
\text { interviewed }\end{array}$ & $\begin{array}{l}\text { 1. Prevalence was } 26.1 \% \text { (overall) and } 40.2 \% \\
(\geqslant 40 \text { years old); } \\
\text { 2. Several medical conditions, including } \\
\text { cardiovascular diseases, diabetes and } \\
\text { hyperlipidemia, correlate with the prevalence of } \\
\text { ED; } \\
\text { 3. Lifestyle factors such as cigarette smoking are } \\
\text { additional concomitant risk factors. }\end{array}$ \\
\hline Liu et al. (2009) ${ }^{8}$ & $\begin{array}{l}\text { Carrying out a prospective study investigating } \\
\text { changes in the epidemiological } \\
\text { characteristics of ED outpatients from } 2003 \\
\text { to } 2008\end{array}$ & IIEF & 858 subjects from 11 cities in China & $\begin{array}{l}\text { 1. Longer ED disease course (5-10 years) was } \\
\text { associated with moderate and severe ED and a } \\
\text { higher incidence of hypertension or diabetes; } \\
\text { 2. The incidence of ED in } 2008 \text { was much more } \\
\text { higher compared with in } 2003 \text { ( } 73.3 \% \text { versus } \\
57.6 \% \text { ) among those who were not satisfied with } \\
\text { their sexual lives; } \\
\text { 3. Increased unhealthy living habits (such as } \\
\text { smoking and drinking) had an additive impact on } \\
\text { the incidence and severity of ED. }\end{array}$ \\
\hline
\end{tabular}

Abbreviations: CIEF, Chinese Index of Erectile Function; DM, diabetes mellitus; ED, erectile dysfunction; IIEF, International Index of Erectile Function.

and concluded that diagnostic approaches to ED should be individualized, which is safer, more economical and more practical.

\section{Treatment of ED in China}

The PDE5is have brought ED therapy into a new era. In China, three PDE5is have been introduced in the last decade. The first Chinese clinical trial of sildenafil, the first PDE5i introduced in China, was published in 2001. ${ }^{13}$ It was a double-blind, randomized, placebo-controlled, parallel-group, multi-centre, flexible dose escalation study of sildenafil oral tablets $(25,50$ and $100 \mathrm{mg})$ taken over an 8 -week period. A total of 628 subjects were enrolled and randomized. The primary efficacy variables (questions 3 and 4 from the IIEF questionnaire) revealed a statistically significant improvement over placebo, with an effective rate of $80.8 \%$ on sildenafil vs. $40.1 \%$ on placebo $(P<0.0001)$. The global assessment question was whether treatment could improve erections. The results revealed that improved erection was achieved in $89.2 \%$ of patients on sildenafil vs. $37.4 \%$ on placebo. Additionally, sildenafil was well tolerated. The results obtained from this study are similar to those from other countries.

Two years later, the phase IV results of a trial for sildenafil therapy for ED patients were published in China. ${ }^{14}$ This study showed that 
most ED patients, including patients with diabetes, cardiac disease, etc., were satisfied with the treatment.

Vardenafil, another PDE5i, came to China in 2003, and the clinical study was published in $2005 .{ }^{15}$ It was also a multicentre, randomized, double-blind and placebo-controlled study. A total of 624 men with mild-to-severe ED were enrolled in this trial for 12 weeks of treatment with either placebo or vardenafil at 5, 10 or $20 \mathrm{mg}$ on demand. The percentage of successful intercourse was between $59 \%$ and $71 \%$ for the three dosage groups. The primary drug-related adverse events were flushing $(9 \%-13 \%)$ and headache/dizziness $(7 \%-13 \%)$, which were mild and self-relievable.

The clinical trial of tadalafil in China was published in $2006 .{ }^{16}$ This study assessed the efficacy and safety of on-demand tadalafil for the treatment of ED in South-East Asian men enrolled from China, Singapore and the Philippines $(n=367)$. Compared with placebo, tadalafil significantly improved ED for all efficacy outcomes $(P<0.001)$. Patients who received tadalafil at 10 or $20 \mathrm{mg}$ experienced significant mean improvements, with IIEF scores of 8.1 and 8.7 , respectively. Of patients who received tadalafil at 10 or $20 \mathrm{mg}, 81 \%$ and $86 \%$, respectively, reported improved erections at the endpoint compared with $44 \%$ in the placebo group $(P<0.001)$. The most common adverse effects reported by patients were headache, back pain, dyspepsia and dizziness.

With the rise of PDE5is, additional studies were published. A large sample, multi-centre study on the prevalence of ED in type 2 diabetic men, with an evaluation of the efficacy and safety of sildenafil, was published in $2005 .{ }^{17}$ As measured using total IIEF-5 scores, the prevalence of ED in diabetic patients is $75.2 \%$. The prevalences of severe, moderate and mild ED are $9.1 \%, 17.2 \%$ and $48.9 \%$, respectively. The overall efficacy of oral sildenafil therapy is $86.4 \%$. This study indicates that $\mathrm{ED}$ is a very common complication in male diabetic patients, and it is positively associated with age, $\mathrm{HbAlC}$ and the duration of diabetes. Treatment with sildenafil for ED is effective and is well tolerated by men with diabetes.

In 2000, the MUSE of PGE1 was studied in China. ${ }^{18}$ Although positive results were reported, it was not introduced into the Chinese market. In recent years, additional studies on the daily use of PDE5i have been published, and this approach has proven to be effective in treating some patients.

Traditionally, most ED patients in China do not accept penile prosthesis implantation, and this attitude has grown in the PDE5i era. Given that PDE5 inhibitors are ineffective in more than $10 \%$ of ED patients, prostheses are an alternative choice for these patients. Because of the increasing prevalence of PCa in China, the incidence of ED following radical prostatectomy will become more common, and some of these patients will not be cured by oral PDE5 inhibitors. In a large-scale study, Xin et al. ${ }^{19}$ reported a satisfying result for penile prosthesis implantation in these patients.

Traditional Chinese medicine therapy for ED is preferred by some patients, especially by elderly patients in China. Although most traditional Chinese medicine is not as effective as PDE5is, some studies have reported that traditional Chinese medicine is a promising treatment for ED. ${ }^{20}$

\section{Basic research}

Basic science research of ED in China has focused on gene therapy in recent years. For example, Zhao et al. ${ }^{21}$ reported that the adenovirusmediated expression of antisense cDNA from the promoter of the human PDE5A1 gene can improve erectile function in rabbits with diabetes mellitus. Gene therapy is a potential treatment strategy for ED patients in the next decade. Although encouraged by the promising future of gene therapy, we believe that additional hard work is required from Chinese urologists and andrologists. At the same time, we realize that there are still many technical hurdles which should be overcome before gene therapy becomes available for the treatment of patients.

\section{PROSTATE DISEASES}

Prostatitis, benign prostatic hyperplasia (BPH) and PCa are the three most common urological diseases in China. These three diseases, and PCa in particular, are hot topics, not only in clinical trials but also in basic research. A search of the Chinese National Knowledge Infrastructure database retrieves 3912, 2424 and 4627 references from 2001 to 2010 for PCa, BPH and prostatitis, respectively.

The incidence of BPH and PCa shows a significant upward trend year by year. $\mathrm{Gu}^{22}$ investigated the urological hospitalisation incidence of $\mathrm{BPH}$ and PCa in 30 districts of Mainland China in 1997. BPH and PCa patients account for $16.1 \%$ and $1.5 \%$ of urological in-patients among 187 hospitals. The incidence of hospitalisation for $\mathrm{BPH}$ and $\mathrm{PCa}$ in one hospital increased from $7.6 \%$ and $0.6 \%(1951-1960)$ to $18.5 \%$ and $3.4 \%$ (1991-1997), respectively. Li et al. ${ }^{23}$ analysed the populationbased cancer registration data between 1998 and 2002, and these data suggest that the annual incidences of PCa were 1.96, 3.09 and 4.36 per 100000 people during 1998-1992, 1993-1997 and 1998-2002, respectively. PCa seems to be the top urological cancer in large cities in China.

The Chinese Urological Association and the Chinese Androgical Association issued guidelines for $\mathrm{PCa}, \mathrm{BPH}$ and prostatitis, and the diagnosis and treatment of the prostatic diseases have been standardized according to these guidelines. Prostate-specific antigen (PSA) detection and transrectal ultrasonography are available throughout the country. $\mathrm{Li}$ and $\mathrm{Na}^{24}$ studied the sensitivity of PSA levels for detecting PCa in Chinese men (Table 2).

Table 2 The sensitivity of PSA levels for detecting PCa in Chinese men $^{24}$

\begin{tabular}{ll}
\hline PSA level & Positive biopsy rates (\%) \\
\hline $\begin{array}{l}\text { tPSA }<4 \mathrm{ng} \mathrm{ml}^{-1} \text { with positive digital } \\
\text { rectal examination }\end{array}$ & $18.1(13 / 72)$ \\
tPSA 4-10 $\mathrm{ng} \mathrm{ml}^{-1}$ with f/tPSA $\geqslant 0.16$ & $11.6(10 / 86)$ \\
tPSA 4-10 $\mathrm{ng} \mathrm{ml}^{-1}$ with t/fPSA $<0.16$ & $17.4(45 / 258)$ \\
tPSA 10.1-20 ng ml & $24.9(110 / 442)$ \\
tPSA $>20 \mathrm{ng} \mathrm{ml}^{-1}$ & $24.9(110 / 442)$ \\
\hline
\end{tabular}

Abbreviations: f/tPSA, free/total prostate-specific antigen ratio; $\mathrm{PCa}$, prostate cancer; PSA, prostate-specific antigen; tPSA, total prostate-specific antigen.

Gan et al. ${ }^{25}$ studied the clinical value of the exfoliative cytology of prostatic fluid in the diagnosis of PCa. Prostatic fluid cytology has a specificity of $100 \%$ and a sensitivity of $42.8 \%$ with PSA $>20 \mathrm{ng} \mathrm{ml}^{-1}$. Cai et al. ${ }^{26}$ investigated the predictive accuracy of different Partin tables in Chinese PCa patients. They concluded that Partin tables 1997, 2001 and 2007 accurately predict the pathological feature of seminal vesicle involvement. However, only Partin table 1997 is able to accurately predict organ-confined diseases. To study the correlations between clinical examinations and latent PCa, Liu et al. ${ }^{27}$ found that for adults with abnormal PSA values, combination with magnetic resonance imaging examination is more valuable for directing puncture during the follow-up period. When investigating the impact of different prostate biopsy strategies on tumour detection, Shan et al. ${ }^{28}$ concluded that a protocol for 10 core biopsies that combines cores at the base, mid-gland and apex of the prostate with lateral base and mid cores should be the preferred strategy in the early detection of PCa. 
Radical resection of $\mathrm{PCa}$ and radiotherapy remain the primary treatment for localized PCa. Open surgery and laparoscopic prostatectomy are the most commonly used procedures. Robotic surgery is also available at a few institutes. Hong et al. ${ }^{29}$ found that clinical stage is an independent risk factor for a positive surgical margin, and other risk factors include high Gleason score, tPSA higher than $20 \mathrm{ng} \mathrm{ml}^{-1}$ and positive digital rectal examination. Orchiectomy is the most common method for the treatment of metastatic PCa, whereas medical castration as a technique for treatment is becoming much more common, especially in big cities. Qiu et al. ${ }^{30}$ reported that the average castrate testosterone level in patients with advanced PCa is less than $1.9 \mathrm{nmol}^{-1}$ after bilateral orchiectomy. PSA level decreases gradually and reaches its nadir at around 6 months. Docetaxel-based chemotherapy is the first-line treatment for hormone-refractory PCa. Chen et al. ${ }^{31}$ analysed survival rates for three common treatment methods for PCa. In all 494 patients studied, disease-specific survival rates for 1 -, 3- and 5-year periods were $90 \%, 89 \%$ and $80 \%$, respectively. Disease-specific survival rates at year 3 were $92.4 \%$ for brachytherapy, $100 \%$ for radical prostatectomy and $80.6 \%$ for hormone therapy. Multivariate analysis indicates that stage, PSA level and age have significant impacts on specific disease survival.

Although chronic prostatitis is a common urological disease in young males presenting at outpatient clinics, He et al. ${ }^{32}$ surveyed 121 urologists in Hunan Province in Southern China using a selfadministered questionnaire and found no consistent consensus on the aetiology and pathogenesis of chronic prostatitis among urologists and andrologists. This has resulted in wide variations in disease diagnosis and treatment practices. Patients with chronic prostatitis typically have psychological problems. Wu et al. ${ }^{33}$ investigated the psychological status of 1500 patients with chronic prostatitis. They found that when cutoff points were set at $\geqslant 50$ (the self-rating anxiety scale) and $\geqslant 53$ (self-rating depression scale), 337 patients $(23.6 \%)$ had symptoms of anxiety and 309 patients $(21.7 \%)$ had symptoms of depression. Zhang et al. ${ }^{34}$ conducted a population-based cross-sectional survey. A total of 4285 men (95.2\%) completed the survey, the results of which indicated that chronic prostatitis-like symptoms exert a significant impact on the quality of life, especially among the younger population. The degree of impairment of the quality of life correlates with the NIH-CPSI, character, life pressure, course, etc. Hu et al. ${ }^{35}$ investigated bacterial pathogenesis in chronic prostatitis and found that $56.1 \%$ of patients have a positive bacteria culture in the prostatic fluid, among which Gram-positive bacteria are more common. Chen et al. ${ }^{36}$ found that there is no linear correlation between the severity of symptoms and the amount of white blood cells and small particles of lecithin in expressed prostatic secretion. Clinical symptoms should be the main factor for evaluating the diagnosis and curative effect.

Drug therapy with alpha-blocker and 5-alpha-reductase inhibitors is most commonly used to treat BPH patients in China. Some patients would prefer to take traditional herbal medicine. Surgical procedures for the treatment of $\mathrm{BPH}$ vary from institute to institute. Transurethral resection of the prostate is the major procedure for $\mathrm{BPH}$ in large cities, while open surgery remains the main procedure in the countryside. Prostate enucleation with a plasmakinetic system and a laser system is encouraged in some institutes because of the positive clinical outcomes.

\section{RECENT PROGRESS IN RESEARCH INTO MALE CONTRACEPTION IN CHINA}

The only methods currently available for male contraception are coitus interruptus, condoms and vasectomy, which have been used since the nineteenth century. Many studies have repeatedly demonstrated that a richer assortment of contraceptive options leads to increased usage and reduced fertility. There is an urgent need to develop or modify male methods of fertility control to enhance its safety, efficacy, reversibility and acceptability. Recently, Chinese scientists have added surgical approaches to male sterilisation techniques, which are listed as follows.

\section{Obstructive vasal sterilisation}

No-scalpel vasectomy (NSV) and chemical vas occlusion were successfully created by Dr Li in the early 1970s. By the early 1990s, 10 million individuals, ${ }^{37}$ over half a million of them Chinese volunteers, had received NSV and chemical vas occlusion, respectively. In the mid-1990s, the sodium morrhuate injection method was modified by Chinese scientists to require a smaller injection volume $(0.3-$ $0.5 \mathrm{ml} / \mathrm{side}) .{ }^{38}$ However, the longer latency period of sperm disappearance in ejaculates and the reversibility of spermatogenesis are still questionable.

Vas ligation with ring clip was first reported by Dr Han in 1985 in China. The azoospermic rate is $96 \%$ and the complication rate is $0.5 \%$ in a 3-year observation study of 1000 volunteers. ${ }^{39}$ An epidemiological study of the ring clip involving 2028 volunteers in six provinces of China demonstrated that the efficacy and complication rates are $99.4 \%$ and $5.97 \%$, respectively. ${ }^{40}$

As an alternative to vas ligation, electrocoagulation via percutaneous puncture technique creates a firm scar that effectively occludes the ends of the vas. The azoospermic rate of this method is reported to be $98.9 \%-99.1 \%$, and complication rates are $0.7 \%-3.5 \%{ }^{41,42}$ In the late 1990s, based on animal studies, clinical trials using $\mathrm{Ar}^{+}$or Nd:YAG laser irradiation via percutaneous puncture technique, in which a photofibre was guided into the vas lumen, were performed in volunteers seeking male sterilisation. The azoospermic rates reported were $96.8 \%, 99.4 \%$ and $100 \%$ with few complications. ${ }^{43-45}$ The data demonstrate that photocoagulation is a safe, effective and reversible male method of sterilisation with less pain and fewer complications than vasectomy. These studies have established the feasibility of this method. However, there is a lack of prospective, randomized and well-controlled clinical trials to confirm its safety, long-term efficacy and reversibility.

A reversible intra-vas device with a switch was reported by Deng and co-workers in 1994 in China. ${ }^{46}$ This device is $6-7 \mathrm{~mm}$ in length and $1.6,1.4$ and $1.2 \mathrm{~mm}$ in outer diameter for different sizes and consists of a trocar and a core made of stainless steel between which a medical silicone seal is applied to switch on or off the sperm channel. This device can be implanted into the vas lumen and switched on by a surgical process. This device was implanted into 220 volunteers in a clinical trial. The azoospermic rate is $95.6 \%$ and the complication rate is $0.5 \%$. The reversibility of this device remains questionable.

\section{Non-obstructive vasal sterilisation}

Vasectomy is regarded as a permanent male contraceptive method and is based on the complete occlusion of the vas. Some unavoidable complications, including congestive epididymis and sperm granuloma, are believed to originate from complete vas blockage. In order to reduce complications while preserving contraceptive efficacy, many intra-vas devices or chemicals, such as threads, copper wires and styrene maleic anhydride, have been designed to maintain the patency of the vas deferens. Two animal experimental studies using epidural catheters filled with nylon threads and implanted into vas lumen demonstrated good efficacy and reversibility with reduced epididymal 
impairment. ${ }^{47}$ Based on these results, a series of intra-vas devices (IVDs) were made over the past decade. Animal studies and phase I clinical trial indicate good safety and efficacy for these devices. ${ }^{48} \mathrm{~A}$ phase II randomized controlled trial was conducted in China in 2003 to assess the efficacy, safety and acceptability of IVDs compared with NSV. Two hundred and eighty-eight male volunteers seeking vasectomies were randomly assigned to IVD or NSV groups. At the time of the twelfth month follow-up, 140 subjects (97.2\%) in the IVD group and 138 subjects $(95.8 \%)$ in the NSV group received visits and provided semen samples. The azoospermia rate was lower in the IVD group than in the NSV group at this time $(94.3 \%$ in the IVD group versus $98.6 \%$ in the NSV group; $P=0.054) .{ }^{49}$ The reversibility of spermatogenesis after IVD removal was not evaluated in these studies.

Implantation of a filtering nanocopper complex/polymer composite intra-vas device into eight dogs was first reported by Huang and coworkers in 2007 in China. ${ }^{50}$ The size of this device is suitable for canine penis of $14 \mathrm{~mm}$ in length and $0.6 \mathrm{~mm}$ in outer diameter. The sperm concentration is significantly reduced, and no vital sperm is found in the dog's ejaculate. However, there has been no clinical trial reported.

\section{Hormonal male contraception}

The first systematic studies of $\mathrm{T}$ ester as a contraceptive were started in the 1970s. Two large multicentre clinical trials of testosterone enanthate were sponsored by the WHO between 1986 and 1996. ${ }^{51}$ These studies established the feasibility of a hormonal male contraceptive and developed effective monitoring guidelines for the safe conduct of male contraceptive efficacy studies. Over the past decades, $\mathrm{T}$ esters have been tested as contraceptives in thousands of volunteers worldwide.

A new injectable formulation of testosterone undecanoate (TU) extracted from tea seed oil by the Xianju Pharmaceutical Company in China provides a more stable, long-term release of $\mathrm{T}$ into the circulatory system than previously available for testosterone enanthate. In order to assess the long-term safety, contraceptive efficacy and service feasibility of injectable TU by enlargement of sample size and an increase in exposure duration to TU, a phase III clinical trial has been performed in China, sponsored by the WHO and the Chinese government. This project was a prospective, open-label and multicentre clinical trial of hormonal male contraception with WHOstandard monitoring. The trial recruited 1045 normal healthy volunteer couples after screening from 10 centres in China. The results show that there are nine pregnancies in 1554.1 person-years of exposure, for a contraceptive failure rate of 1.1/100 couple years. The combined (primary and secondary) method failure rate is $6.0 \%$. The total failure rate is 7.1/100 couple years. No serious adverse events were reported. Spermatogenesis returned to the normal fertile reference range in all but two subjects. ${ }^{52}$ In a high proportion of healthy fertile Chinese men, monthly injection of $500 \mathrm{mg}$ TU provides safe, effective, reversible and reliable contraception, which may provide a novel and workable alternative to existing family planning options for couples.

Another dose-defining study of depot medroxyprogesterone acetate (DMPA) and TU for the suppression of spermatogenesis was performed in healthy Chinese men. After screening, 30 healthy volunteers were enrolled and randomly assigned to one of three dosage groups ( $n=10 /$ group): $1000 \mathrm{mg}$ TU (Group A), $1000 \mathrm{mg}$ TU plus $150 \mathrm{mg}$ DMPA (Group B), or $1000 \mathrm{mg}$ TU plus $300 \mathrm{mg}$ DMPA (Group C). An 8 -week regimen of TU plus DMPA at both tested combination doses effectively suppresses spermatogenesis to azoospermia in Chinese men. All volunteers tolerated the injections, and no serious adverse effects were reported. ${ }^{53}$
In conclusion, the development of a safe, effective and reversible male contraceptive is urgently needed. Among all male contraceptive methods investigated, novel surgical methods for male sterilisation and hormonal male contraceptives are the closest to clinical application.

\section{MALE INFERTILITY - CURRENT STATUS IN CHINA}

Infertility is not only a major health problem but also a current social problem. The data available over the past 20 years reveal that approximately $10 \%-20 \%$ of couples face reproductive problems, while about $1 \%-15 \%$ of couples remain subfertile in China. It is generally recognized that male infertility is a factor in at least $40 \%-50 \%$ of infertile married couples. The proportion of male infertility may be higher, given the global downward trend in male fertility since the twentieth century due to a variety of factors including environmental pollution, the spread of sexually transmitted diseases, alcoholism, excessive smoking, drug abuse, the abuse of hormone drugs, lifestyle changes, excessive stress and other factors. In China, a similar downward trend has been observed. ${ }^{54-56}$

A retrospective, cross-sectional analysis of infertile couples in Shanghai revealed that the total rate of infertility in the community was $5.04 \% \pm 2.14 \%$, with $3.36 \%$ attributed to primary infertility and $1.68 \%$ to secondary infertility; however, only $39.8 \%$ of women and $38.0 \%$ of men had sought medical help for the problem. Infertile couples are not well educated about reproductive health. The study also indicated that, in addition to helping couples overcome social and economic problems, proper education and clinical and public health interventions are important for the reproductive health of couples. ${ }^{57}$ Another analysis of infertile cases indicates that the incidence of male infertility in certain areas of China is $0.65 \%-10.0 \%$. An epidemiological survey of primary infertility in Guizhou Province ${ }^{54}$ revealed that the prevalence of primary infertility in rural areas is $1.04 \%$. The survey enrolled 100842 couples of reproductive age (aged 15-49 years) from 20 rural townships of nine cities and counties using a stratified cluster random sampling technique. ${ }^{56}$

In 2009, an investigation into infertility was conducted by the Chinese Women and Children Development Center and the China Population Association. The investigation, which lasted 3 months, was primarily conducted through systematic survey, street survey and other forms. More than 18000 effective responses had been received by the end of the investigation. The findings of the investigation revealed that the incidence of infertility is $10 \%$ over 1 year, $15 \%$ over 2 years and $25 \%$ over 10 years. Couples seeking medical aid for problems with infertility were $23-40$ years old. The most common causes for the male infertility included oligospermia and azoospermia. Longterm depression can cause endocrine disorders, resulting in infertility, and a long period of high-intensity radiation can cause infertility. The risk factors for male infertility include abnormal sperm, testicular abnormalities, acquired testicular damage, blockage of sperm transport, endocrine factors, genetic factors, immune factors, genital infections, varicocele, chronic diseases, drug and radiation therapy, toxic chemical substances and environmental impact, tight underwear, excessive drinking, excessive smoking, hypoxic circumstances, etc. ${ }^{58}$

With the rapid development of andrology, it was found that a considerable number of male infertility cases may be associated with genetic abnormalities. A number of studies on male infertility can be grouped into the following two categories: sex chromosome spermatogenesis gene deletion and mutation, and autosomal deletion and mutation of genes. The Y chromosome is the only haploid component of the human genome and has the highest mutation 
rate. The large number of inverted repeat is a genome-destabilizing factor. Many reports have shown that the causes of many nonobstructive azoospermia and severe oligozoospermia (sperm density $<5 \times 10^{6} \mathrm{ml}^{-1}$ ) in patients remain unclear. It is estimated that about $30 \%$ of these patients suffer from genetic disorders such as chromosome aberrations and gene mutations. ${ }^{59}$

Chromosomal abnormalities have an inverse correlation with sperm count. The most common chromosomal abnormalities are polysomy of the $\mathrm{X}$ or $\mathrm{Y}$ chromosome, as has been observed in Klinefelter syndrome and hypogonadism cases. Klinefelter syndrome and microdeletions in the Y-chromosome long arm (particularly the AZFc region deletion) represent the most frequent molecular and genetic causes of severe infertility. Gene mutations involved in male infertility include the cystic fibrosis transmembrane conductance regulator gene, the androgen receptor gene, the insulin-like factor 3 gene and the leucine-rich repeat-containing G-protein coupled receptor 8 gene. Cystic fibrosis transmembrane conductance regulator mutations cause cystic fibrosis, absence of vas deferens and nonobstructive azoospermia. Androgen receptor gene mutations are responsible for androgen insensitivity syndrome and spermatogenetic damage. Insulin-like factor 3 and leucine-rich repeat-containing Gprotein coupled receptor 8 gene mutations have been associated with abnormalities in testis descent and cryptorchidism. Meta-analyses have revealed a significant association between polymorphism and male infertility for partial AZFc deletions, CAG repeat length in the androgen receptor gene, and the methylene tetrahydrofolate reductase gene. $^{60}$

Currently, AZFa deletions are understood to be the result of an intrachromosomal homologous recombination event between two human endogenous retroviral elements. The AZFa deletion interval is approximately $780 \mathrm{~kb}$ in size and contains two genes that are functional only in the male germ line and are associated with Sertoli cellonly (SCO) syndrome. ${ }^{61,62}$

Infertility is frequently considered a difficult emotional experience. Some infertile couples exhibit special psychological characteristics and personality traits such as anxiety, depression, introversion and stubbornness. These factors may affect fertility and the treatment of infertility. Measures such as psychological support from the family and society should be adopted, and psychological intervention should be applied as needed. ${ }^{63}$

Treatments for male infertility include drug therapy, surgery and assisted reproduction. Drug therapy for male infertility includes medications to improve sperm production, treatment against hormonal dysfunction and treatment to cure infections that compromise sperm. The administration of testosterone is similar to that used to treat testosterone deficiency. Tamoxifen, an antiestrogen agent, may be used to stimulate the release of gonadotropin (a male hormone), which leads to testosterone production.

Surgery for male infertility is performed to treat reproductive tract obstruction and varicocele. Vasoepididymostomy is a microsurgical procedure that corrects obstruction in the coiled tube that connects the testes with the vas deferens (epididymis).

Assisted reproduction therapy includes methods to improve ED, induce ejaculation, obtain sperm and inseminate an egg. Intracytoplasmic sperm injection is the milestone for assisted reproduction treatment. In China, there are some famous centres underwent more than 5000 in vitro fertilisation and intracytoplasmic sperm injection cycles each year.

Sperm retrieval is used to obtain sperm from the testes or epididymis when azoospermia is caused by obstruction, congenital absence of the vas deferens, failed vasectomy reversal or inadequate sperm production. This technique includes micro-epididymal sperm aspiration (MESA), percutaneous epididymal sperm aspiration (PESA) and testicular sperm extraction. Sperm retrieved by MESA, PESA or testicular sperm extraction may be used for in vitro fertilisation and intracytoplasmic sperm injection. While excess sperm from MESA or PESA are often frozen for future use, most testicular sperm extraction-derived sperm are not of sufficient quality or quantity for frozen storage (cryopreservation). Multiple MESA or PESA procedures are not recommended, as repetition can lead to scarring.

Although a number of noteworthy clinical and basic research projects on andrology in China remain, we cannot mention them all here. The growing prevalence of PCa will make it the most important urologic cancer in the next decade in China, and male infertility will be of particular concern, not only for patients but also for doctors because of the Chinese traditional culture. In fact, minimally invasive surgical operations such as microsurgical varicocelectomy, transurethral resection of the ejaculatory duct to treat ejaculatory duct obstruction, microsurgical vasovasostomy, microsurgical vasoepididymostomy, etc. are commonly used in the andrology and urology departments of big cities, and a growing number of patients will benefit from these operations.

With a population of 1.3 billion, resources for patients of andrologists and urologists in China will be in high demand, and this presents us with a challenge. However, this also presents us with an opportunity to develop treatments for both Chinese patients and patients worldwide.

1 Zhang ZC, Sun B, Liu YS, Chen Q, Xin ZC et al. The prevalence of erectile dysfunction in 1247 married men in Beijing urban area. Chin J Urol 2003; 24: 855-7.

2 Hu DY, Chen H. Nie XY, Liu MY, Wu Y et al. Prevalence of erectile dysfunction among outpatients in Beijing. Chin J Med Guide 2003; 5: 194-7.

3 Fu JX, Chen BC, Wang WM, Liu CP, Zhu W. The incidence of erectile dysfunction in Nanning and Yulin of Guangxi Province. Chin J Urol 2001; 22: 376-7.

4 Wang JH, Tang CW, Yu XW, Deng XF, Ye HL et al. A prevalence survey of erectile dysfunction in elderly male. Chin J Geriatr 2004; 23: 426-7.

5 Liu L, Liu CS, Pang LN, Shao JB, Wang XJ et al. Analysis of correlative risk factors for diabetic erectile dysfunction in patients. Chin J Diabetes 2006; 14: 450-1.

$6 \mathrm{Xu} Q \mathrm{Q}, \mathrm{Zhu} \mathrm{JJ}$, Jiang H. A clinical analysis of 140 cases of erectile dysfunction. Chin J Urol 2000; 21: 686-7

7 Zhang QJ, Zhu JC, Xu QQ, Jiang $\mathrm{H}$. Male sexual function study in three Chinese cities on 2226 males. Chin J Androl 2003; 17: 191-3.

8 Liu DF, Jiang H, Hong K, Zhao LM, Ma LL et al. Epidemiological changes of ED patients: investigations in 11 Chinese cities during the past 5 years. Natl J Androl 2009; 15: 724-6.

9 Wan Q, Zhu XW, Chen ZD, Xue J, Tang QL et al. NEVA ${ }^{\text {TM }}$ system for diagnosis of erectile dysfunction. Chin J Urol 2002; 23: 699.

10 Li JB, Shen Q, Huang DZ, Zhang QP, Shi XH et al. Evaluation of helicine arteries in patients with erectile dysfunction using color Doppler ultrasonography. Chin J Ultrasound Med 2006; 22: 777-9.

$11 \mathrm{Li} \mathrm{ZH,} \mathrm{Ci} \mathrm{J,} \mathrm{Wang} \mathrm{P,} \mathrm{Kong} \mathrm{CZ,} \mathrm{Liu} \mathrm{TC} \mathrm{et} \mathrm{al.} \mathrm{Application} \mathrm{of} \mathrm{VISER} \mathrm{in} \mathrm{the} \mathrm{diagnosis} \mathrm{of}$ erectile dysfunction. Chin J Urol 2002; 23: 665-6.

12 Bai WJ, Qu HW, Wang XF, Mao X, Sun L et al. Diagnostic approaches of penile erectile dysfunction Chin J Urol 2002; 23: 662-4.

13 Guo YL, Zhu JC, Pan TM, Cao J, Jiang Y et al. Efficacy and safety of oral sildenafil in the treatment of erectile dysfunction. Chin J Urol 2001; 22: 389-94.

14 Phase IV Study Group. Safety and efficacy of viagra in the treatment of erectile dysfunction in a post-marketing study. Chin J Urol 2003; 24: 134-7.

15 Jin J, He ZJ, Zhang K, Zhu JC, Jiang $\mathrm{H}$ et al. The effect of vardenafil, a new potent highly selective phosphodiesterase type 5 inhibitor in the treatment of erectile dysfunction. Chin J Urol 2005; 26: 54-8.

16 Guo YL, Zhu JC, Pan TM, Ding Q, Wang YX et al. Efficacy and safety of on-demand tadalafil for the treatment of erectile dysfunction in South-East Asian men. Int J of Uro 2006; 13: 721-7.

17 The Collaborative Study Group for Multi-Center Clinical Study of ED in China Prevalence of erectile dysfunction in type 2 diabetic men and evaluation of efficacy and safety of sildenafil treatment. Chin J Endocrinol Metab 2005; 21: 348-52. 
18 Jiang $\mathrm{H}, \mathrm{Xu} Q \mathrm{Q}$, Zhu JC. Effect of alprostadil urethral suppository on erectile dysfunction: a double blind, randomized, flexible dose escalation study for 78 patients. Chin J of Androl 2000; 14: 166-9.

19 Xin ZC, GUO YL, Choi HK. A retrospective study of 548 cases of erectile dysfunction treated by penile prosthesis implantation. Chin J Urol 2000; 21: 755-7.

20 Wang Q, Yang JX, Li GX, Xia ZY, Wang B et al. Multi-center and randomly controlled trial of Shuganyiyang capsules for the treatment of erectile dysfunction. J Beijing Univ TCM 2004; 27: 72-5.

21 Zhao YP, Bai WJ, Chen GQ, Liu SJ, Deng QP et al. Adenoviral gene transfer of antisense CDNA of the human PDE5A1 promoter gene to penis enhances erectile function in rabbits with diabetes mellitus. Chin J Urol 2005; 26: 562-5.

22 Gu FL. Epidemiological survey of benign prostatic hyperplasia and prostate cancer in China. J Beijing Med Univ 2000; 32: 30-3.

23 Li M, Zhang SW, Ma JH, Chen WQ, Na YQ et al. A comparative study on incidence trends of prostate cancer in part of cities and counties in China. Chin J Urol 2009; 30: 368-70.

$24 \mathrm{Li} \mathrm{M}, \mathrm{Na} Y \mathrm{YQ}$. The detection rate of prostate cancer in different prostate-specific antigen (PSA) levels in Chinese men. Natl Med J China 2008; 88: 16-8.

25 Gan WM, Chen HW, Wang ZM, Zhang N, Taiji N et al. Clinical significance of cytology of prostatic fluid in diagnosis of prostate carcinoma. J Fourth Mil Med Univ 2007; 28: 1677-9.

26 Cai L, Zhou LQ, He ZS, Li NC, Song Y et al. Predictive accuracy of different Partin tables in Chinese prostate cancer patients. Chin J Urol 2009; 30: 202-6.

27 Liu T, Wang XY, Wang Y. Multivariate survival analysis model of prostate cancer with a cox model. J Peking Univ (Health Sci) 2009; 41: 184-7.

28 Shan ZG, Jin J, Guo YL. Impaction of different prostate biopsy strategies on tumor detection. Chin J Urol 2006; 27: 40-2.

29 Hong K, Ma LL, Huang Y, Wang GL, Liu L. Risk factors for positive surgical margins in extraperitoneal laparoscopic radical prostatectomy. Chin J Urol 2008; 29: 272-4.

30 Qiu Z, Sun YC, Shao Q, Zhang Y, Du LD. Assessment of castrate testosterone levels in patients with advanced prostate cancer. Chin J Urol 2006; 27: 125-7.

31 Chen J, Xu DF, Gao T, Ren JZ, Yao YC et al. The survival and prognosis of three common treatments for prostate carcinoma and the factors impacting on them. China Oncol 2009; 19: 512-6.

32 He LY, Wang Y, Tang YX, Jiang XZ. A survey of urologist's and andrologist's diagnostic and treatment practices for chronic prostatitis in Hunan Area. Chin J Androl 2008; 22: 9-11.

33 Wu LX, Liang CC, Tang ZG, Hao ZY, Liu P et al. Epidemiological study on psychological problems of 1426 patients with chronic prostatitis. Chin J Urol 2006; 27: 512-5.

34 Zhang TF, Liang CC, Ge WW, Hao ZY, Zhang XS et al. Impact of chronic prostatitis-like symptoms on quality of life of patients. Anhui Med J 2009; 30: 2-5.

$35 \mathrm{Hu}$ XP, Bai WJ, Zhu JC, Wang XF. A pathogenic and immunologic study of chronic prostatitis. Chin J Urol 2002; 23: 29-31.

36 Chen GH, Li LQ, Wang CH, Zhou Q, Hu LS. Correlation between the symptom index of chronic prostatitis and the amount of WBC and SPL in prostatic secretion. Chin J Human Sex 2009; 18: 17-8.

37 Liu XZ, Li SQ. Vasal sterilization in China. Contraception 1993; 48: 255-65.

38 Zhang LC, Li XA, Feng XS, Chai XG, He JB et al. Antifertility effect induced by small dosage injection of sodium morrhuate toward epididymis via vas deferens. Natl $J$ Androl 1994; 1: 20-3.

39 Fan JC, Wei GY. Clinical analysis of 1000 male sterilization volunteers with ring clip. $J$ Binzhou Med Coll 2001; 24: 282-3.

40 Shi QZ, Liu YR, Zhou RX. Epidemiological study on effect and safety of vas ligation with ring clip. J Binzhou Medical Coll 1991; 1: 7 .

41 Yi EB, Mao PX, Zhao L, Zhao ZX, Yuan XS et al. The electric coagulation vasectomy for sterilization: an experimental study and its clinical application. Chin J Androl 1988; 3: 6.
42 Yin SG, Zhang $\mathrm{CH}$, Liu HJ. Analysis of 347 male sterilization with electric coagulation. J Binzhou Med Coll 1997; 20: 185-6.

43 Sun ZH, Yin SG, Li DR, Zhang B, Wu SH et al. Clinical study of laser photocoagulation for vas occlusion. Chin J Surg 2005; 2: 112-4.

44 Yin SG, Sun ZH, Liu HJ, Zhang H, Wang YQ. A study of $\mathrm{Ar}^{+}$laser photocoagulation for vas occlusion: 58 cases report. Chin J Androl 2006; 20: 55

45 Xiao XM, Zhang DY, Xiao H, Wang PX, Yang ZW et al. The experiment and clinical observation of laser ductus deferens contraception. Chin J Androl 2008; 22: 15-8.

46 Deng YG, Hou YH, Yang YF, Zhou CL, Liu SZ. Clinical study of reversal intra-vas device with switch. Reprod Med 1994; 3: 53.

47 Liu XH, Zhan BY, Wu RY. Histological and ultrastructural observations on testes and epididymis in rhesus monkeys after two vasal contraceptive operations. Nan Xing Xue Za Zhi 1992; 6: 70-3.

48 Ye Y, Chen ZW, Xing ZJ, Wu YW. Experimental study of intra vas device for male sterilization in rat. Chin J Fam Plann 1998; 12: 543-5.

49 Song L, Gu Y, Lu W, Liang X, Chen Z. A phase II randomized controlled trial of a novel male contraception, an intra-vas device. Int J Androl 2006; 29: 489-95.

50 Huang XB, Suo JP, Chen CY, Dun QL, Shun JY et al. Influence of filtering nano-copper complex/polymer composites intra-vas device on the semen of male dog. Reproduction Contracept 2007; 27: 31-3.

51 World Health Organization Task Force for the Regulation of Male Fertility. Contraceptive efficacy of testosterone-induced azoospermia and oligozoospermia in normal men. Fertil Steril 1996; 65: 821-9.

52 Gu YQ, Liang XW, Wu WX, Peng L, Song SX et al. Multicenter contraceptive efficacy trial of injectable testosterone undecanoate in Chinese men. J Clin Endocrinol Metab 2009; 94: 1910-5.

53 Gu YQ, Tong JS, Ma TZ, Liu ML, Yuan D et al. Male hormonal contraception: effects of injections of testosterone undecanoate and depot medroxyprogesterone acetate at 8-week intervals in Chinese men. J Clin Endocrinol Metab 2004; 89. 2254-62.

54 Jian NM, Li YB, Feng L, Xin LM, Hong CL. An epidemiological survey on the primary infertility in Guizhou Province. Chin J of Fam Plann 2010; 1: 33-5.

55 Chen LF, Wang MZ, Yang WX, Gan SX, Tong ZJ et al. An epidemiological survey and clinical research on the primary infertility in Henan Province. Reprod Contracept 1992; 12: 51-4.

56 Xu YJ, Liu DM, Su QC, Sun MZ, Tian KW. An epidemiological investigations on the primary infertility of the three rural in Shandong Province. Chin J Fam Plann 2000; 65: 414-24.

57 Wang YB, Liu YH, Zhang YW. Study on current status of infertile couples in Zhabei District of Shanghai. Chin J Fam Plann 2002; 7: 410-3.

58 Chinese Women and Children Development Center and the China Population Association. Investigation on Infertility in China. Beijing: Chinese Women and Children Development Center and the China Population Association; 2009.

59 Vogt PH. Molecular genetics of human male infertility: from genes to new therapeutic perspectives. Curr Pharm Des 2004; 10: 471-500.

60 Xia XY, Yang B, Cui YX, Huang YF. Genetic causes of male infertility. Natl J Androl 2008; 14: 837-41.

61 Zhang J, Qiu SD. Male infertility-related genes. Int J Fam Plann (Reprod Health) 2006; 25: 221-4

62 Wang LQ, Huang HF, Jin F, Qian YL, Cheng Q. High frequency of $Y$ chromosome microdeletions in idiopathic azoospermic men with high follicle-stimulating hormone levels. Fertil Steril 2005; 83: 1050-2.

63 Liu XR, Li SW, Li L. Research progress in the psychological aspects and related interventions in infertile couples. J Reprod Med 2005; 14: 125-8. 